\section{High Temperature Magnetic Susceptibility of Light Rare-Earth Tungstates}

\author{
Naseeb Dar and H. B. Lal \\ Department of Physics, University of Gorakhpur, India
}

Z. Naturforsch. 34a, 892-894 (1979);

received April 30, 1979

This paper reports our results on the magnetic susceptibility $\left(\chi_{\mathrm{m}}\right)$ of light rare-earth (viz. Ce, $\mathrm{Pr}, \mathrm{Nd}, \mathrm{Sm}, \mathrm{Eu}$ and $\mathrm{Gd}$ ) tungstates in the temperature range of 300 to $900 \mathrm{~K}$. As expected the variation of $\chi_{\mathrm{m}}$ with temperature obeys the Curie-Weiss law $\left(\chi_{\mathrm{m}}=C / T-\theta\right)$. The values of the Curie-constant $(C)$, paramagnetic Curie temperature $(\theta)$ and magneton number $(p)$ for the magnetic ions of these tungstates have been evaluated. The experimental $p$ values are in good agreement with the theoretical values of $p$ for these ions. Thus it is concluded that the magnetic (4f) electrons remain intact with the respective ions at high temperature and their participation in electrical conduction is improbable. Negative values of $\theta$ normally indicate antiferromagnetic ordering in these compounds at low temperatures; however in these tungstates the crystal field seems to be the prime reason for Curie-Weiss law behaviour and negative values of $\theta$. The magnetic behaviour of light rare-earth tungstates in briefly discussed.

\section{Introduction}

Rare-earth compounds have become very interesting from theoretical and experimental points of view. Many of the rare-earth compounds are useful in permanent magnet and laser materials, optical filters, microwave computers and space technology $[1-4]$. We have been studying the electrical and magnetic properties of rare-earth sesquioxides $[5,6]$, tungstates [7-12] and molybdates [13] for the last six years. This paper reports on our study regarding the molar magnetic susceptibility $\left(\chi_{\mathrm{m}}\right)$ of light rare-earth (viz. Ce, Pr, Nd, Sm, Eu and Gd) tungstates in the temperature range of 300 to $900 \mathrm{~K}$. At room temperature these tungstates have monoclinic lattice structure [14] and belong to space group $F_{2} / d$. All of them are fine grained powders with typical colours. To the best of our knowledge the magnetic properties of these compounds have not been studied by other workers.

\section{Materials and Experimental Techniques}

These tungstates with a stated purity of $99.9 \%$ have been procured from Rare-Earth Products

Reprint requests to Dr. N. Dar, Department of Physics, University of Gorakhpur, Gorakhpur, Indien.

$0340-4811 / 79 / 0700-0892 \$ 01.00 / 0$
Limited, England. They have been used as such in our study.

The magnetic susceptibility $\left(\chi_{\mathrm{m}}\right)$ at high temperatures $(T>300 \mathrm{~K})$ of these powdered samples was measured using Faraday's method employing a sensitive magnetic balance $\left(10^{-5} \mathrm{~g}\right)$ and electromagnets of typical pole pieces. The procedural details are described elsewhere [15]. The accuracy of the $\chi_{\mathrm{m}}$ values at high temperatures is $\sim 3 \%$ whereas at low temperatures it is $<2 \%$.

\section{Results and Discussion}

The variation of $\chi_{\mathrm{m}}^{-1}$ of light rare-earth tungstates with temperatures is shown in Figure 1. The curves for all the samples are good straight lines, suggesting Curie-Weiss law behaviour $\left(\chi_{\mathrm{m}}=C / T-\theta\right)$ and a possible magnetic ordering at low temperatures [16]. From the extrapolation of these straight lines and their slopes one can obtain values of the paramagnetic Curie temperature $(\theta)$ and Curieconstant $(C)$. From the value of $C$ the effective Bohr magneton $(p)$ for the magnetic ions has been calculated. The calculated values of these parameters are given in Table 1.

In these tungstates only rare-earth ions are magnetic in nature and are presumed to exist in trivalent states. From the ground state L, S and $J$ values of these ions one can evaluate [17] the free ion theoretical values of $p$. These values are also given in Table 1 for all the light rare-earth tungstates. There is good agreement between the free ion theoretical and experimental values of $p$ except for the $\mathrm{Sm}$ and Eu tungstates. However Van Vleck and Frank [17] have reported the effective $p$ values for these magnetic ions, which are in agreement with our experimental values. This agreement indicates that the $4 \mathrm{f}$ electrons are intact on their respective ions and thus their participation in electrical conduction is least probable.

It is clear from Table 1 that the light rare-earth tungstates have negative value of $\theta$, which indicates possible antiferromagnetic ordering at low temperatures [16]. The insulating nature of these compounds $\left(\sigma \sim 10^{-10} \mathrm{ohm}^{-1} \mathrm{~cm}^{-1}\right.$ at room temperature) [15] rules out any direct exchange interaction between the rare-earth ions. Also it has been shown by various workers $[16,18]$ that other types of exchange interaction are very weak between the rare-earth ions. Dipole interactions are also expected to be very weak in view of the large 


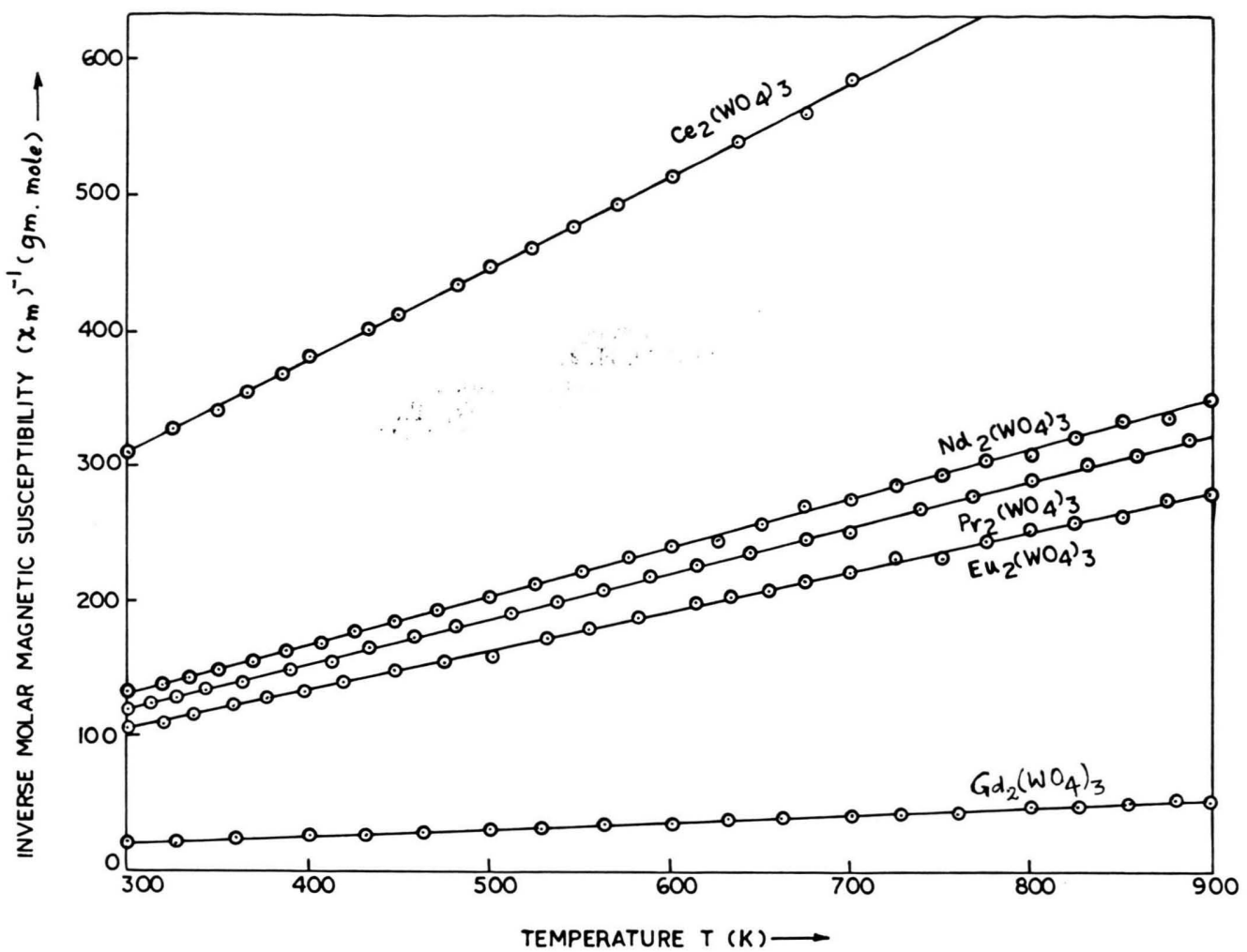

Fig. 1. Variation of inverse molar magnetic susceptibility $\left(\varkappa_{\mathrm{m}}\right)^{-1}$ of light rare-earth tungslates from 300 to $900 \mathrm{k}$.

separation between these ions. Thus this negative value of $\theta$ is not expected due to magnetic ordering. The $\chi_{\mathrm{m}}$ of $\mathrm{Sm}_{2}\left(\mathrm{WO}_{4}\right)_{3}$ is very weak at $300 \mathrm{~K}$ and we could not measure it accurately. However, our low temperature magnetic susceptibility results [8] too speak against exchange interaction and antiferromagnetic ordering, otherwise the inverse molar susceptibility of this compound ought to have risen and not fallen with decreasing temperature. In view of these facts it can be said that the finite value of $\theta$ is dominantly caused by crystal field interactions and not by superexchange or double exchange interactions. This is clearly seen in $\mathrm{Gd}_{2}\left(\mathrm{WO}_{4}\right)_{3}$. This compound has the magnetic ion $\mathrm{Gd}^{3+}$ which is spherically symmetric being in the orbital $\mathrm{S}$ state. Thus it has very small crystal field interaction giving $\theta=0$ only if other interactions are negligible.

\section{Acknowledgement}

One of us (N.D.) is grateful to CSIR (India) for a Post-Doctoral Fellowship.

Table 1. Calculated values of different parameters and experimental $p$ values.

\begin{tabular}{|c|c|c|c|c|c|c|c|}
\hline \multirow[t]{2}{*}{ Tungstates } & \multirow{2}{*}{$\begin{array}{l}\text { Magnetic } \\
\text { ion }\end{array}$} & \multirow{2}{*}{$\begin{array}{l}\text { Ground } \\
\text { state }\end{array}$} & \multirow{2}{*}{$\begin{array}{l}\text { Molar Curie- } \\
\text { constant } \\
\mathrm{Cm} \\
\text { (K/emu-mole) }\end{array}$} & \multirow{2}{*}{$\begin{array}{l}\text { Paramagnetic } \\
\text { Curie- } \\
\text { temperature } \\
\theta(\mathbf{K})\end{array}$} & \multicolumn{3}{|c|}{ Effective Bohr magneton $p$} \\
\hline & & & & & $\begin{array}{l}\text { Theoretical } \\
\text { free ion }\end{array}$ & $\begin{array}{l}\text { Van-Vleck } \\
\text { and Frank }\end{array}$ & $\begin{array}{l}\text { Experi- } \\
\text { mental }\end{array}$ \\
\hline $\mathrm{Ce}_{2}\left(\mathrm{WO}_{4}\right)_{3}$ & $\mathrm{Ce}^{3+}$ & ${ }^{2} \mathrm{~F}_{5 / 2}$ & $1.50 \pm 0.15$ & $-160 \pm 5$ & 2.53 & 2.56 & $2.45 \pm 0.10$ \\
\hline $\mathrm{Pr}_{2}\left(\mathrm{WO}_{4}\right)_{3}$ & $\mathrm{Pr}^{3+}$ & ${ }^{3} \mathrm{H}_{4}$ & $3.06 \pm 0.15$ & $-65 \pm 5$ & 3.58 & 3.62 & $3.50 \pm 0.10$ \\
\hline $\mathrm{Nd}_{2}\left(\mathrm{WO}_{4}\right)_{3}$ & $\mathrm{Nd}^{3+}$ & ${ }^{4} \mathrm{I}_{9 / 2}$ & $3.10 \pm 0.15$ & $-60 \pm 5$ & 3.62 & 3.68 & $3.54 \pm 0.10$ \\
\hline $\mathrm{Sm}_{2}\left(\mathrm{WO}_{4}\right)_{3}$ & $\mathrm{Sm}^{3+}$ & ${ }^{6} \mathrm{H}_{5 / 2}$ & $0.70 \pm 0.20$ & $-30 \pm 5$ & 0.84 & 1.60 & $1.65 \pm 0.13$ \\
\hline $\mathrm{Eu}_{2}\left(\mathrm{WO}_{4}\right)_{3}$ & $\mathrm{Eu}^{3+}$ & ${ }^{7} \mathrm{~F}_{0}$ & $2.95 \pm 0.15$ & $-40 \pm 5$ & 0.00 & 3.50 & $3.44 \pm 0.10$ \\
\hline $\mathrm{Gd}_{2}\left(\mathrm{WO}_{4}\right)_{3}$ & $\mathrm{Gd}^{3+}$ & $8 \mathrm{~S}_{7 / 2}$ & $15.80 \pm 0.10$ & $0.0 \pm 1$ & 7.94 & 7.94 & $7.95 \pm 0.06$ \\
\hline
\end{tabular}


[1] S. Methfessel and D. C. Mattice, Handbuch der Physik XVII/1, Ed. S. Flugges, Springer-Verlag Heidelberg, 1960 , p. 389 .

[2] K. N. R. Taylor, Contemp. Phys. 11, 423 (1970) and Adv. Phys. 20, 551 (1971).

[3] F. H. Spedding, Fifteenth edition of Encyclopedia Britannica. Inc. Printed in USA, Helen Hemingway Publisher 1974, p. 515.

[4] H. W. Katz, Solid State Magnetic and Dielectric Devices, John Wiley, New York 1959.

[5] N. Dar and H. B. Lal, Ind. J. Pure Appl. Phys. 14, 788 (1976).

[6] H. B. Lal, B. K. Verma, and N. Dar, Ind. J. Cryogenics 1, 119 (1976).

[7] H. B. Lal, N. Dar, and A. Kumar, J. Phys. C 7, 4335 (1974) and 8, 2745 (1975).

[8] H. B. Lal and N. Dar, Z. Naturforsch. 30a, 1783 (1975).

[9] H. B. Lal and N. Dar, Physica 84B, 254 (1976).
[10] H. B. Lal and N. Dar, J. Phys. Chem. Solids 38, 161 (1977).

[11] H. B. Lal, N. Dar, and L. Lundgren, J. Phys. Soc. Japan 41, 1216 (1976)

[12] N. Dar and H. B. Lal, Pramana 11, 705 (1978).

[13] H. B. Lal and R. N. Pandey, Z. Naturforsch. 33 a, 235 (1978).

[14] K. Nassau, H. J. Levinstein, and G. M. Loiacono, J. Phys. Chem. Solids 26, 1805 (1965).

[15] N. Dar, Electrical Transport and Magnetic Properties of some Rare-Earth compounds, Ph. D. Thesis, University of Gorakhpur, Gorakhpur 1976.

[16] D. H. Martin, Magnetism in Solids, Illeffe Book Ltd., London 1967, p. 201.

[17] J. H. Van Vleck, Theory of Electric and Magnetic Susceptibility, Oxford University Press, London 1932, p. 226.

[18] J. H. Thomas and M. J. Seinko, J. Chem. Phys. 61, 3920 (1974). 